\title{
Proliferative Activity and Apoptosis in Thymic Epithelial Neoplasms
}

Kenzo Hiroshima, M.D., Akira Iyoda, M.D., Tetsuya Toyozaki, M.D., Yana Supriatna, M.D., Kiyoshi Shibuya, M.D., Fumihiko Shimamura, M.D., Yukiko Haga, M.D., Shigetoshi Yoshida, M.D., Takehiko Fujisawa, M.D., Hidemi Ohwada, M.D.

Departments of Basic Pathology (KH, TT, KS, FS, YH, HO), Thoracic Surgery (AI, SY, TF), and Molecular Pathology (YS), Graduate School of Medicine, Chiba University, Chiba, Japan

The classification of thymic epithelial tumors is controversial because prediction of the biological behavior of these tumors from their morphologic appearance is difficult. The aim of this study was to evaluate the proliferative activity and rate of apoptosis of thymic epithelial tumors classified according to World Health Organization histological classification. We also attempted to determine the importance of a number of proapoptotic factors in these processes. We investigated 46 surgically resected thymic epithelial tumors (8 Type A, 8 Type AB, 7 Type B1, 7 Type B2, 6 Type B3, and 10 Type C). Immunohistochemical staining was performed to determine the tumor expression of p53 protein, Bax, Bcl-2, and survivin. In addition, the Ki-67 labeling index (LI) and apoptotic index (AI) of these tumors were evaluated. Type $\mathrm{C}$ thymoma had a higher LI $(16.55 \pm 12.12 \%)$ than did the other histological subtypes. Stage IV thymoma (12.36 \pm 9.99\%) had a higher LI than did Stage I tumor. The AI was significantly elevated in Type B1 thymoma $(1.47 \pm 0.55 \%)$. Overexpression of $\mathrm{p53}$ protein was observed in Type B3 and C thymomas. p53 proteinpositive tumors had a higher LI than did p53 protein-negative tumors $(P<.0001)$. Bcl-2 expression was observed in Type $\mathrm{A}, \mathrm{AB}$, and $\mathrm{C}$ thymomas. Bcl2-positive thymoma had a lower AI than did Bcl-2negative thymoma $(P=.0157)$. These results suggest that overexpression of $\mathrm{p} 53$ protein is associated with a higher tumor proliferative activity and that Bcl-2 acts as an inhibitor of apoptosis in thymoma.

Copyright () 2002 by The United States and Canadian Academy of Pathology, Inc.

VOL. 15, NO. 12, P. 1326, 2002 Printed in the U.S.A.

Date of acceptance: September 3, 2002.

Partially supported by Smoking Research Foundation.

Address reprint requests to: Kenzo Hiroshima, M.D., Department of Basic Pathology, Graduate School of Medicine, Chiba University, 1-8-1 Inohana, Chuo-ku, Chiba, 260-8670 Japan; e-mail: kenzo@med.m.chibau.ac.jp; fax: 81-43-226-2180.

DOI: $10.1097 / 01 . M P .0000038463 .67854 .84$
Bcl-2 and p53 protein expression may be useful markers in differentiating thymoma subtypes.

KEY WORDS: Apoptosis, bax, bcl-2, Ki-67, p53, Survivin, Thymic carcinoma, Thymoma.

Mod Pathol 2002;15(12):1326-1332

The classification of thymoma and thymic carcinoma remains controversial. Levine and Rosai (1) have proposed that a Type I malignant thymoma is a tumor with features characteristic of thymoma and evidence of local invasion, or lymphatic or hematogenous metastasis, and that a Type II malignant thymoma is a tumor that is obviously malignant by cytological examination. Marino and Müller-Hermelink (2) have divided thymoma into cortical, medullary, and mixed types based on the microscopic features of the epithelial cells. More recently, Kirchner and Müller-Hermelink (3) recognized a well-differentiated thymic carcinoma (WDTC). A simple classification of thymic epithelial tumors based on their degree of differentiation has also been proposed by Suster and Moran (4).

Recently, the World Health Organization (WHO; 5) proposed a new classification that represents a compromise between the various approaches. Thymomas are classified into two major types of thymoma depending on whether the neoplastic epithelial cells and their nuclei have a spindle or oval shape (Type A) or have a plump appearance (Type B). Type B thymomas are further subdivided based on the proportion of neoplastic cells (B1, B2, and B3). Type $C$ thymoma (thymic carcinoma) is a thymic tumor exhibiting clear-cut cytologic atypia and cytoarchitectural features analogous to those observed in carcinomas of other organs.

Several oncogenes and tumor-suppressor genes are known to regulate apoptosis. For example, bcl-2, part of a gene family capable of promoting or inhibiting apoptosis, is activated by dimerizing with bax and inhibits apoptosis $(6,7)$. However, an excess of bax protein promotes apoptosis (8), and bax 
expression is up-regulated by the p53 protein (9). The p53 protein normally mediates apoptosis, with mutation resulting in increased cell survival (10). Survivin is a member of a family of inhibitors of apoptosis proteins (11). It has been implicated in the regulation of cell cycle in the G2/M phase (12).

The size of a tumor cell population depends on the balance between cell growth and cell death and in particular, on the rate of tumor cell apoptosis. Evidence indicates that variation in this balance contributes to carcinogenesis (13). Although previous studies of thymic epithelial tumors have used staining for proliferating cell nuclear antigen (PCNA), nucleolar organizing regions (AgNORs), or Ki-67 antigen to demonstrate increased cell proliferation (14-16), few have evaluated the rate of apoptosis or the balance between proliferation and apoptosis within these tumors.

The aim of this study was to investigate the frequency of cell proliferation and apoptosis in thymomas and the influence of p53 protein, Bax, Bcl-2, and survivin expression on these processes. Cell proliferation was evaluated by immunohistochemical detection of Ki-67 antigen, which is expressed in the cell nucleus during the G1, S, G2, and M phases of the cell cycle (17). Apoptosis was detected by 3 '-end labeling of nuclear DNA via the terminal deoxynucleotidyl transferase-mediated dUTP nick end labeling (TUNEL) assay, which detects not only cells with the typical morphological features of apoptosis but also cells in the early stages of apoptosis (18). We determined the rate of cell proliferation and apoptosis in thymic epithelial tumors that were classified according to the WHO classification.

\section{MATERIALS AND METHODS}

Forty-six cases of thymic epithelial tumors from patients who had surgical thymectomy between July 1991 and September 2001 were examined in this study. Paraffin tissue blocks and clinical history were available for all 46 patients. The age of patients at operation ranged from 26 to 83 years (average, $56.3 \mathrm{y}$ ). There were 18 men and 28 women. All cases (Table 1) were subclassified histologically based on the WHO histological classification (5),

TABLE 1. Distribution of Thymic Epithelial Tumors Classified According to the WHO Histological Classification and the Staging System of Masaoka et al. (19)

\begin{tabular}{cccccc}
\hline $\begin{array}{c}\text { Histological } \\
\text { Subtype }\end{array}$ & Stage I & Stage II & Stage III & Stage IV & Total \\
\hline A & 5 & 1 & 2 & 0 & 8 \\
AB & 3 & 4 & 0 & 1 & 8 \\
B1 & 1 & 6 & 0 & 0 & 7 \\
B2 & 0 & 3 & 1 & 3 & 7 \\
B3 & 1 & 1 & 3 & 1 & 6 \\
C & 0 & 3 & 4 & 3 & 10 \\
\hline
\end{tabular}

and patients were staged according to the staging system of Masaoka et al. (19). They comprised 8 cases of Type A, 8 of Type AB, 7 of Type B1, 7 of Type B2, 6 of Type B3, and 10 of Type C thymoma. Thymic tissues from 8 patients with myasthenia gravis were also analyzed. The follow-up period ranged from 5 months to 9 years and 7 months (mean follow-up, $4 \mathrm{y}, 5 \mathrm{mo}$ ).

\section{Immunohistochemical Staining}

All thymic tumors were examined after immunohistochemical staining. Four-micrometer sections were cut from formalin-fixed paraffin-embedded tissues and placed on silanized slides (DAKO, Glostrup, Denmark). They were stained with the monoclonal antibody DO-7 (1:1600; DAKO), which reacts with both wild-type and mutant p53 protein, polyclonal anti-human Bax protein (1:200; DAKO), monoclonal anti-Bcl-2 oncoprotein (1:800; DAKO), polyclonal anti-survivin (1:50; Alpha Diagnostic, San Antonio, TX), and a monoclonal antibody against Ki-67 antigen (MIB-1; 1:100; Immunotech, Marseille, France). The streptavidin-biotin method (Histofine SAB-PO Kit, Nichirei, Tokyo, Japan) was used for immunostaining. To improve the staining pattern, the tissues were pretreated by microwave treatment for 15 minutes in citrate buffer $(10 \mathrm{~mm}$ pH 6.0) before staining with DO-7, Bcl-2, and MIB-1 and by autoclave at $121^{\circ} \mathrm{C}$ for 15 minutes before staining with Bax and survivin. DO-7 immunoreactivity was classified as positive when the proportion of positively stained cells was $>10 \%$ of all tumor cells. Expression of Bax, Bcl-2, and survivin was considered to be positive if there was staining of areas of the epithelial component of the tumor. Ki-67 labeling indices (LI) were determined by light microscopy using an oil-immersion objective (magnification, $1000 \times$ ) by randomly counting $\geq 1000$ tumor nuclei and expressing the results as the percentage of positive cells.

\section{3'-End Labeling of DNA in Apoptotic Cells}

The TUNEL assay was performed as described elsewhere (20). The apoptotic index (AI) was defined as the sum of the number of apoptotic cells and apoptotic bodies divided by the total number of tumor cells. A total of $\geq 1000$ tumor nuclei was examined by light microscopy with an oil immersion objective (magnification, 1000×) for each specimen.

\section{Statistical Analysis}

All statistical calculations were carried out using the StatView software package (SAS Institute Inc., Cary, NC). Differences in the Ki-67 LI and AI among subtypes of thymic epithelial tumors were analyzed 
by a one-way factorial ANOVA and multiple comparison test (Tukey-Kramer test), and differences in the expression of DO7, Bax, Bcl-2, and survivin were analyzed by the chi-square test. Differences in Ki-67 LI and AI related to the expression of DO-7, Bax, Bcl-2, and survivin were analyzed using the Student's $t$ test. Statistical significance was defined as $P<.05$.

\section{RESULTS}

A representative result of immunohistochemical staining with MIB-1 (for Ki-67 antigen) is shown in Figure 1A. The Ki-67 LI for each subtype are listed in Table 2. There was a significant difference in the Ki-67 LI among the WHO subtypes $(P<.0001)$. By multiple comparative analyses, these differences were between Type $C$ thymoma $(16.55 \pm 12.12 \%)$ and thymic epithelium, Type A, AB, B1, B2, and B3 thymomas. There was also a significant association between the Ki-67 LI and tumor stage ( $P=.0422$; Table 3). By multiple comparative analyses, there was a significant difference between Stage I (2.68 \pm $2.06 \%)$ and Stage IV (12.36 $\pm 9.99 \%)$.

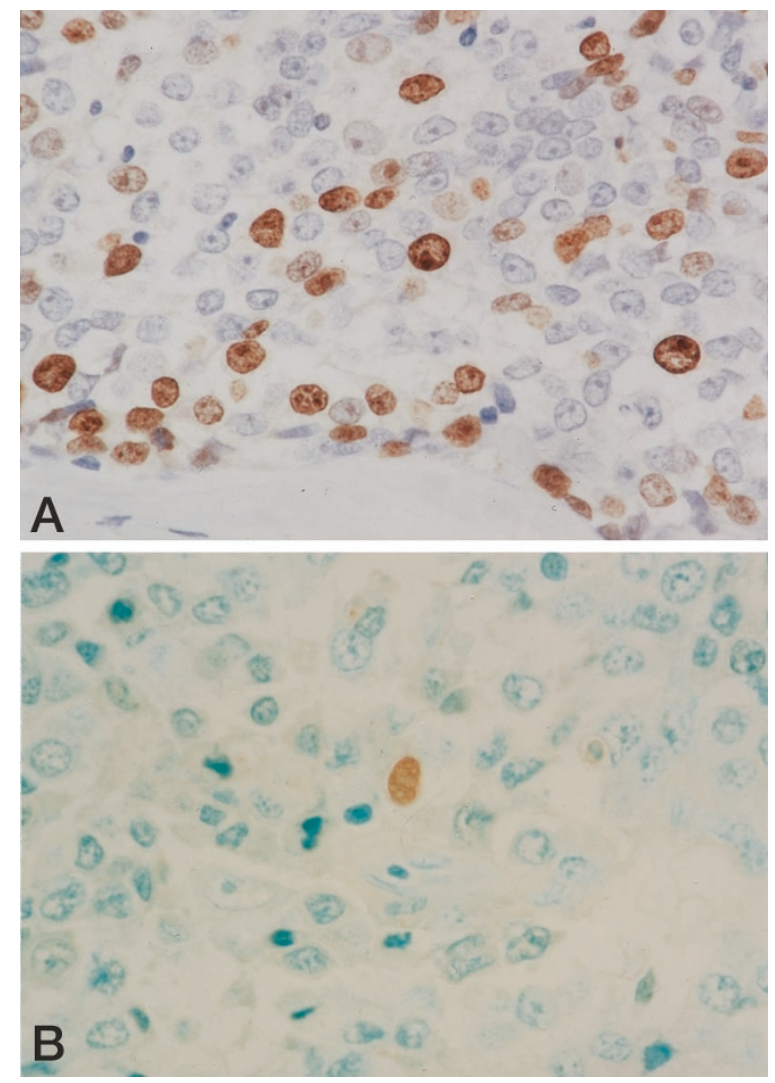

FIGURE 1. A, immunohistochemical staining for Ki-67 in a case of thymic carcinoma. Ki-67 was detected within the nuclei of the cancer cells; Ki-67-positive cancer cells were frequently observed. Hematoxylin was used for counterstaining (original magnification, $100 \times$ ). B, TUNELpositive reaction observed in the nuclei of cancer cells in a case of thymic carcinoma. Methyl green was used for counterstaining (original magnification, $100 \times)$.
TABLE 2. Ki-67 Labeling Indices and Apoptotic Indices of Thymic Epithelial Tumors Classified According to the WHO Histological Classification

\begin{tabular}{cccc}
\hline Subtypes & No. of Cases & LI \% (Mean \pm SD) & AI \% (Mean \pm SD) \\
\hline N & 8 & $2.87 \pm 0.82$ & $0.15 \pm 0.16$ \\
A & 8 & $1.16 \pm 0.60$ & $0.52 \pm 0.64$ \\
AB & 8 & $4.51 \pm 2.90$ & $0.67 \pm 0.64$ \\
B1 & 7 & $4.72 \pm 2.57$ & $1.47 \pm 0.55^{b}$ \\
B2 & 7 & $6.41 \pm 2.98$ & $0.88 \pm 0.83$ \\
B3 & 6 & $7.00 \pm 3.15$ & $0.91 \pm 0.72$ \\
C & 10 & $16.55 \pm 12.12^{a}$ & $0.62 \pm 0.62$ \\
\hline
\end{tabular}

$\mathrm{N}$, thymic epithelium; LI, labeling indices; AI, apoptotic indices; SD, standard deviation.

${ }^{a}$ The LI of Type $\mathrm{C}$ thymoma was significantly higher than that observed in thymic epithelium, Type A, AB, B1, B2, and B3 thymoma.

${ }^{b}$ The AI of Type B1 thymoma was significantly higher than that observed in thymic epithelium.

TABLE 3. Ki-67 Labeling Indices and Apoptotic Indices in Thymic Epithelial Tumors Classified According to the Staging System of Masaoka et al. (19)

\begin{tabular}{cccc}
\hline Stages & No. of Cases & LI \% (Mean \pm SD) & AI \% (Mean \pm SD) \\
\hline I & 10 & $2.68 \pm 2.06$ & $0.58 \pm 0.59$ \\
II & 18 & $6.76 \pm 6.30$ & $1.13 \pm 0.72$ \\
III & 10 & $8.33 \pm 8.64$ & $0.55 \pm 0.63$ \\
IV & 8 & $12.36 \pm 9.99^{a}$ & $0.75 \pm 0.70$ \\
\hline
\end{tabular}

LI, labeling indices; AI, apoptotic indices; SD, standard deviation.

${ }^{a}$ LI observed in Stage IV was significantly higher than that observed in Stage I tumors.

A representative TUNEL result is shown in Figure 1B. The AI for each subtype is listed in Table 2 . There were significant differences in the AI among the WHO subtypes $(P=.0092)$. By multiple comparative analyses, the AI of Type B1 thymoma was significantly higher than that of thymic epithelium. The AI of Type A, AB, B2, B3, and C thymoma tended to be higher than that of thymic epithelium and lower than that of Type B1 thymoma, but the difference was not significant. There was no association between tumor AI and tumor stage (Table $3)$.

Representative results of immunohistochemical staining using antibodies to p53 protein, Bax, Bcl-2, and survivin are shown in Figure $2 \mathrm{~A}-\mathrm{D}$, and a summary of the results is listed in Table 4 . The immunoreactivity of DO-7, Bax, and Bcl-2 was significantly different among WHO subtypes $(P=.0016, P$ $=.0001, P<.0001$, respectively). Overexpression of DO-7 ( $>10 \%$ of tumor cells staining positive) was observed in Type B3 and C thymomas only. Expression of Bcl-2 was observed in Type $A, A B$, and $C$ thymomas but not in Type B1, B2, or B3 thymomas. Type $\mathrm{C}$ thymomas had intensely positive Bcl-2 staining, but the spindle tumor cells in Type A and $\mathrm{AB}$ thymoma were only weakly positive. There was a significant association between thymoma Bax immunoreactivity and tumor stage $(P=.0232$, Table $5)$.

There was a significant association between tumor sample overexpression of DO-7 and the Ki-67 

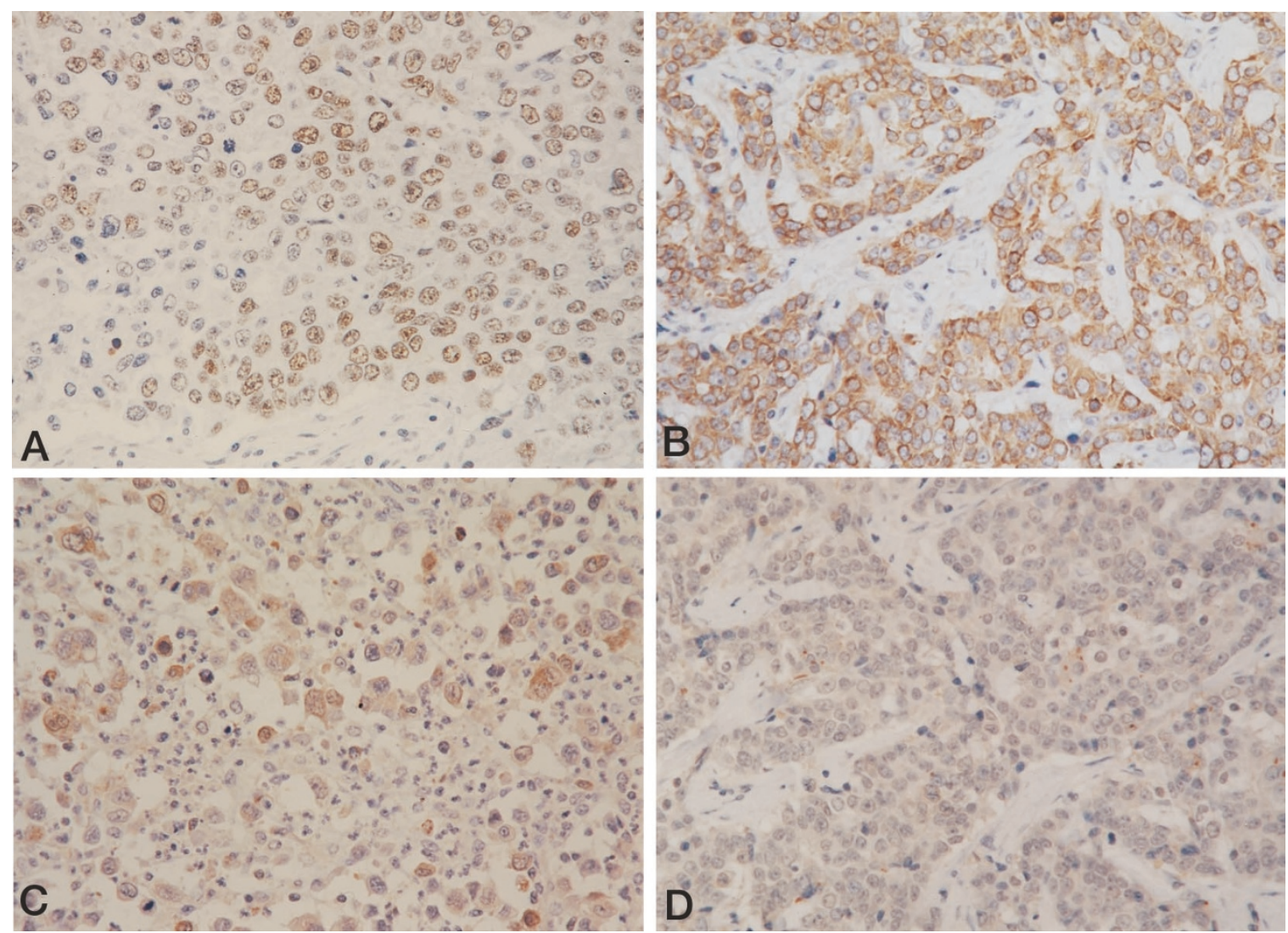

FIGURE 2. Immunohistochemical staining for DO-7, Bcl-2, Bax, and survivin in thymic carcinoma. A, the nuclei of numerous carcinoma cells stained positive with the monoclonal antibody DO-7. B, diffuse strong Bcl-2 expression was observed in the cytoplasm of cancer cells from a case of thymic carcinoma. C, diffuse Bax expression was observed in the cytoplasm of cancer cells from a thymic carcinoma. D, diffuse survivin expression was observed in the cytoplasm of cancer cells from a case of thymic carcinoma. Hematoxylin was used for counterstaining (original magnification, $50 \times)$.

TABLE 4. Results of Immunohistochemical Staining of Thymic Epithelial Tumors Classified According to the WHO Histological Classification

\begin{tabular}{ccccccc}
\hline Subtypes & Type A & Type AB & Type B1 & Type B2 & Type B3 & Type C \\
\hline DO7 & & & & & & \\
positive & 0 & 0 & 0 & 0 & 2 & 6 \\
negative & 8 & 8 & 7 & 7 & 4 & 4 \\
Bax & & & & & & \\
positive & 6 & 3 & 1 & 5 & 6 & 9 \\
negative & 2 & 5 & 6 & 2 & 0 & 1 \\
Bcl-2 & & & & & & \\
positive & 8 & 4 & 0 & 0 & 0 & 9 \\
negative & 0 & 4 & 7 & 7 & 6 & 1 \\
Survivin & & & & & & \\
positive & 7 & 7 & 0 & 7 & 6 & 10 \\
negative & 1 & 1 & 7 & 0 & 0 & 0 \\
\hline
\end{tabular}

Immunostaining for DO-7, Bax, and Bcl-2 was significantly different among WHO thymoma types $(P=.0016, P=.0001$, and $P<.0001$, respectively).

LI $(P<.0001)$. However, there was no relationship between tumor overexpression of DO-7 and the tumor AI (Table 6). We found an inverse association between the expression of Bcl-2 and the AI in thymic epithelial tumors $(P=.0157)$; however, no relationship was observed between tumor expression of Bcl-2 and the tumor Ki-67 LI (Table 6). There were no significant relationships between the tu-
TABLE 5. Results of Immunohistochemical Staining of Thymic Epithelial Tumors Classified According to the Staging System of Masaoka et al. (19)

\begin{tabular}{ccccc}
\hline Stages & Stage I & Stage II & Stage III & Stage IV \\
\hline DO7 & & & & \\
positive & 0 & 3 & 2 & 2 \\
negative & 10 & 15 & 8 & 6 \\
Bax & & & & \\
positive & 8 & 7 & 9 & 6 \\
negative & 2 & 11 & 1 & 2 \\
Bcl-2 & & & & \\
positive & 7 & 6 & 6 & 2 \\
negative & 3 & 12 & 4 & 6 \\
Survivin & & & & \\
positive & 8 & 12 & 10 & 7 \\
negative & 2 & 6 & 0 & 1 \\
\hline
\end{tabular}

Immunostaining for Bax protein showed significant differences in Bax expression among thymomas staged according to the criteria of Masaoka et al. $(19 ; P=.0232)$.

mor expression of Bax or survivin and tumor LI or AI.

The prognosis of thymic epithelial tumors for patients in this study was good. One patient with a Type AB, Stage IVb thymoma had pulmonary metastasis 26 months after surgery, and one patient with a Type C, Stage III thymoma had local recurrence 22 months after surgery, but both are still 
TABLE 6. The Relationships between the Ki-67 Labeling Index or the Apoptotic Index and DO-7, Bax, Bcl-2, or Survivin Expression in Thymic Epithelial Tumors

\begin{tabular}{|c|c|c|c|c|c|}
\hline Immunoreactivity & No. of Cases & LI \% (Mean \pm SD) & $P$ Value & $\mathrm{AI} \%($ Mean $\pm \mathrm{SD})$ & $P$ Value \\
\hline \multicolumn{6}{|l|}{ DO-7 } \\
\hline negative & 38 & $4.67 \pm 3.08$ & \multirow[t]{2}{*}{$<0.0001$} & $0.78 \pm 0.70$ & \multirow[t]{2}{*}{0.3840} \\
\hline positive & 8 & $19.15 \pm 12.31$ & & $1.02 \pm 0.72$ & \\
\hline \multicolumn{6}{|l|}{ Bax } \\
\hline negative & 16 & $4.93 \pm 3.52$ & \multirow[t]{2}{*}{0.1584} & $0.90 \pm 0.63$ & \multirow[t]{2}{*}{0.5711} \\
\hline positive & 30 & $8.39 \pm 9.26$ & & $0.77 \pm 0.74$ & \\
\hline \multicolumn{6}{|l|}{ Bcl-2 } \\
\hline negative & 25 & $7.13 \pm 6.70$ & \multirow[t]{2}{*}{0.9563} & $1.04 \pm 0.70$ & \multirow[t]{2}{*}{0.0157} \\
\hline positive & 21 & $7.26 \pm 9.27$ & & $0.55 \pm 0.61$ & \\
\hline \multicolumn{6}{|l|}{ Survivin } \\
\hline negative & 9 & $5.02 \pm 3.11$ & \multirow[t]{2}{*}{0.3623} & $1.15 \pm 0.79$ & \multirow[t]{2}{*}{0.107} \\
\hline positive & 37 & $7.72 \pm 8.61$ & & $0.74 \pm 0.66$ & \\
\hline
\end{tabular}

LI, labeling indices; AI, apoptotic indices; SD, standard deviation.

alive. One patient with a Type C, Stage IVb thymoma died 14 months after surgery. Other patients are alive and without recurrence during the follow-up period, which ranges from 5 months to 9 years and 7 months (mean follow-up, 4 y, 5 mo).

\section{DISCUSSION}

It is the balance between cell gain through mitosis and cell loss by apoptosis, which determines whether a tumor mass increases in size or regresses (13). A parallel increase in the rate of apoptosis and proliferation has been reported in studies of the histological progression of colorectal cancers (21, 22) and cervical neoplasms (23). A decrease in apoptosis occurs during progression from adenoma to carcinoma in the colorectum $(21,22)$ and during progression from intraepithelial neoplasia to carcinoma in the prostate (24). We have previously reported that immature teratomas exhibited higher proliferative activity but lower rates of apoptosis than mature teratomas (20).

We undertook the present study to determine whether histological subtypes of thymic epithelial tumors, classified according to the WHO classification, demonstrated differing rates of proliferation and/or apoptosis. The proliferation index has been used previously as an important indicator of the biological behavior of tumors. Studies evaluating PCNA and AgNORs have demonstrated significant differences in tumor staining for PCNA and AgNORs between thymic carcinoma and thymomas but not between noninvasive and invasive thymomas $(14,15)$. In contrast, Yang et al. (16) reported that WDTC (Type B3 thymoma) showed a significantly higher Ki-67 LI when compared with medullary type (Type A thymoma). Here we found a statistically significant difference in the Ki-67 LI between Type $\mathrm{C}$ thymomas and other subtypes of thymomas. There was also a nonsignificant trend towards an increase in the Ki-67 LI from Type A, Type AB, Type B1, and Type B2, to Type B3.
A previous study indicated that the AI of highgrade thymic carcinomas was higher than those of thymomas and WDTC (25). However, our results showed that the AI of BI thymoma was significantly higher than that of thymic epithelium. The AI of Type $\mathrm{A}, \mathrm{AB}, \mathrm{B} 2, \mathrm{~B} 3$, and Type $\mathrm{C}$ thymomas also tended to be higher than that of thymic epithelium, but these differences were not significant. In particular, the AI of thymic carcinoma was not higher than that of other subtypes and was in fact low compared with that of Type B1 thymoma. These differing results may be due to the wide range of $\mathrm{Al}$ within each subtype. Further studies with larger number of cases are required to clarify the importance of apoptosis in thymomas.

Our results showed that the proliferative activity and rate of apoptosis in thymomas was higher than those observed in thymic epithelium. Both the proliferative activity and the rate of apoptosis were lower in Type A thymomas compared with other subtypes. In contrast, in Type C thymoma, the proliferative activity was higher than in other subtypes, but the rate of apoptosis was not increased, resulting in a net increase in tumor mass.

Chen et al. (26) reported that the Bcl-2 reactivity of thymic carcinoma was significantly higher than that observed in noninvasive and invasive thymomas. They also suggested that because all medullary thymomas exhibited Bcl-2 reactivity, Bcl-2 expression could not be used as an indicator of the invasive behavior of thymoma when applying the classification of Marino and Müller-Hermelink (2). Our study confirmed that Bcl-2 expression was observed only in Type $\mathrm{A}, \mathrm{AB}$, and $\mathrm{C}$ thymomas. In addition, we found that the intensity of reactivity in Type $\mathrm{A}$ and $\mathrm{AB}$ thymomas was weak, whereas that of Type $C$ thymoma was strong. Our results suggest that Bcl-2 expression may be a useful marker in differentiating Type B3 thymoma from Type C thymoma, and Type A thymoma from Type B3 thymoma. 
Recent studies indicate that tumor cells undergo apoptosis and that both p53 and bcl-2 are key regulators of this process. Wild-type p53 protein induces apoptosis, whereas expression of Bcl-2 inhibits apoptosis $(6,9,27)$. We found that tumors staining positive for Bcl-2 expression had a lower AI than Bcl-2 negative tumors. However, tumors with immunohistochemical evidence of overexpression of p53 protein had a similar AI as that of p53negative tumors. These findings suggest that Bcl-2 continues to function as an inhibitor of apoptosis despite tumor progression but that p53 protein no longer influences the rate of apoptosis. A similar tendency has been observed in gastric carcinoma (28).

The expression of survivin was reported to be inversely correlated with the AI during colorectal tumorigenesis (22). We found no similar correlation in this study of thymomas.

Wild-type p53 protein enhances p21WAF1 transcription, which inhibits the cyclin/CDK complex; thereby arresting cell cycle (29). Thus the loss of p53 function in tumor cells may result in an increase in cell cycling. Many studies have investigated the link between p53 overexpression and tumor growth. Some have reported a positive relationship (30-32), whereas others have not $(33,34)$. We observed an increase in the LI with an increase in p53 expression, suggestive of an association between p53 overexpression and proliferative activity in thymic epithelial tumors.

Tateyama et al. (35) reported that all thymic epithelial tumors, including noninvasive thymomas, demonstrated overexpression of p53 protein. Here, overexpression of p53 protein was observed only in Type B3 and C thymomas, suggesting that overexpression of p53 protein may be useful as a marker for these more aggressive subtypes.

Although the incidence of overexpression of DO-7, Bax, and survivin was similar in Type B3 and C thymoma, the Ki-67 LI of Type B3 thymoma was lower. The A1 of Type B3 thymoma was, however, higher than that of Type $C$ tumors, which may be related to the relative increase in Bcl-2 staining of Type $\mathrm{C}$ tumors. Type B3 thymoma has been known as WDTC because of its invasiveness (3), but the degree of atypia is similar to that observed in Type B2 thymoma. Our studies of LI, and expression of DO-7, Bax, and survivin of Type B3 and C would suggest that these subtypes have similar but not identical genetic aberrations and that the biological behavior of the former is different from the latter.

Lardinois et al. (36) reported that the Marino and Müller-Hermelink (2) and Masaoka et al. (19) classifications were both independent significant predictors of overall and disease-free survival in patients with epithelial thymic tumors. Okumura et al. (37) have suggested that WHO classification may aid in predicting tumor recurrence. In our study, one patient with a Type $\mathrm{C}$ thymoma died of the tumor, and tumor recurrence was observed in another patient with a Type $\mathrm{C}$ thymoma and pulmonary metastasis in a patient with a Type $A B$ thymoma. There were no other tumor recurrences observed during the mean follow-up of 4.5 years. Postoperatively, patients received radiotherapy for Stages II-IV in our institute. Thus, it appears that even patients with invasive thymic epithelial tumor may have a good prognosis if the tumor is resected completely and they undergo radiotherapy.

Acknowledgments: The authors thank Ms. Ayaka Sato, Ms. Tamiyo Taniguchi, and Ms. Kazuko Abe for their technical assistance.

\section{REFERENCES}

1. Levine GD, Rosai J. Thymic hyperplasia and neoplasia: a review of current concepts. Hum Pathol 1978;9:495-515.

2. Marino M, Müller-Hermelink HK. Thymoma and thymic carcinoma. Relation of thymoma epithelial cells to the cortical and medullary differentiation of thymus. Virchows Arch A Pathol Anat Histopathol 1985;407:119-49.

3. Kirchner T, Müller-Hermelink HK. New approaches to the diagnosis of thymic epithelial tumors. In: Fenoglio-Preiser CM, Wolff M, Rike F, editors. Progress in surgical pathology. Vol. 10. Philadelphia: Field and Wood; 1989. p. 167-89.

4. Suster S, Moran CA. Thymoma, atypical thymoma, and thymic carcinoma. A novel conceptual approach to the classification of thymic epithelial neoplasms. Am J Clin Pathol 1999;111:826-33.

5. Rosai J, Sobin LH. World Health Organization. Histological typing of tumours of the thymus. 2nd ed. Berlin: SpringerVerlag; 1999.

6. Hockenbery D, Nunez G, Milliman C, Schreiber RD, Korsmeyer SJ. Bcl-2 is an inner mitochondrial membrane protein that blocks programmed cell death. Nature 1990;348:334-6.

7. Yin XM, Oltvai ZN, Korsmeyer SJ. BH1 and BH2 domains of Bcl-2 are required for inhibition of apoptosis and heterodimerization with Bax. Nature 1994;369:321-3.

8. Oltvai ZN, Milliman CL, Korsmeyer SJ. Bcl-2 heterodimerizes in vivo with a conserved homolog, Bax, that accelerates programmed cell death. Cell 1993;74:609-19.

9. Miyashita T, Reed JC. Tumor suppressor p53 is a direct transcriptional activator of the human bax gene. Cell 1995; 80:293-9.

10. Levine AJ. p53, the cellular gatekeeper for growth and division. Cell 1997;88:323-31.

11. Ambrosini G, Adida C, Altieri DC. A novel anti-apoptosis gene, survivin, expressed in cancer and lymphoma. Nat Med 1997;3:917-21.

12. Li F, Ambrosini G, Chu EY, Plescia J, Tognin S, Marchisio PC, et al. Control of apoptosis and mitotic spindle checkpoint by survivin. Nature 1998;396:580-4.

13. Wyllie AH. The biology of cell death in tumours. Anticancer Res 1985;5:131-6.

14. Rahilly MA, Edwards CW, Crocker J, Murray P. Epithelial cell type, clinical behavior and AgNOR counts in thymic epithelial tumours. Anal Cell Pathol 1991;3:203-13.

15. Tateyama H, Mizuno T, Tada T, Eimoto T, Hashimoto T, Masaoka A. Thymic epithelial tumours: evaluation of malignant grade by quantification of proliferating cell nuclear 
antigen and nucleolar organizing regions. Virchows Arch A Pathol Anat Histopathol 1993;422:265-9.

16. Yang WI, Efird JT, Quintanilla-Martinez L, Choi N, Harris NL. Cell kinetic study of thymic epithelial tumors using PCNA (PC10) and Ki-67 (MIB-1) antibodies. Hum Pathol 1996;27: $70-6$.

17. Gerdes J, Lemke H, Baisch H, Wacker HH, Schwab U, Stein $\mathrm{H}$. Cell cycle analysis of a cell proliferation-associated human nuclear antigen defined by the monoclonal antibody Ki-67. J Immunol 1984;133:1710-5.

18. Migheli A, Attanasio A, Schiffer D. Ultrastructural detection of DNA strand breaks in apoptotic neural cells by in situ end-labelling techniques. J Pathol 1995;176:27-35.

19. Masaoka A, Monden Y, Nakahara K, Tanioka T. Follow-up study of thymomas with special reference to their clinical stages. Cancer 1981;48:2485-92.

20. Hiroshima K, Toyozaki T, Iyoda A, Yusa T, Fujisawa T, Ohwada H. Apoptosis and proliferative activity in mature and immature teratomas of the mediastinum. Cancer 2001; 92:1798-806.

21. Sinicrope FA, Roddey G, McDonnell TJ, Shen Y, Cleary KR, Stephens LC. Increased apoptosis accompanies neoplastic development in the human colorectum. Clin Cancer Res 1996;2:1999-2006.

22. Kawasaki H, Toyoda M, Shinohara H, Okuda J, Watanabe I, Yamamoto T, et al. Expression of survivin correlates with apoptosis, proliferation, and angiogenesis during human colorectal tumorigenesis. Cancer 2001;91:2026-32.

23. Isacson C, Kessis TD, Hedrick L, Cho KR. Both cell proliferation and apoptosis increase with lesion grade in cervical neoplasia but do not correlate with human papillomavirus type. Cancer Res 1996;56:669-74.

24. Berges RR, Vukanovic J, Epstein JI, CarMichel M, Cisek L, Johnson DE, et al. Implication of cell kinetic changes during the progression of human prostatic cancer. Clin Cancer Res 1995; 1:473-80.

25. Tateyama H, Eimoto T, Tada T, Inagaki H, Hattori H, Takino H. Apoptosis, bcl-2 protein, and Fas antigen in thymic epithelial tumors. Mod Pathol 1997;10:983-91.

26. Chen FF, Yan JJ, Jin YT, Su IJ. Detection of bcl-2 and p53 in thymoma: expression of bcl-2 as a reliable marker of tumor aggressiveness. Hum Pathol 1996;27:1089-92.
27. Yonish-Rouach E, Resnitzky D, Lotem J, Sachs L, Kimchi A, Oren M. Wild-type p53 induces apoptosis of myeloid leukaemic cells that is inhibited by interleukin-6. Nature 1991;352: 345-7.

28. Aizawa K, Ueki K, Suzuki S, Yabusaki H, Kanda T, Nishimaki $\mathrm{T}$, et al. Apoptosis and Bcl-2 expression in gastric carcinomas: correlation with clinicopathological variables, p53 expression, cell proliferation and prognosis. Int J Oncol 1999; 14:85-91.

29. Harper JW, Adami GR, Wei N, Keyomarsi K, Elledge SJ. The p21 Cdk-interacting protein Cip1 is a potent inhibitor of G1 cyclin-dependent kinases. Cell 1993;75:805-16.

30. Ikeguchi M, Saito H, Katano K, Tsujitani S, Maeta M, Kaibara N. Clinicopathologic significance of the expression of mutated p53 protein and the proliferative activity of cancer cells in patients with esophageal squamous cell carcinoma. J Am Coll Surg 1997;185:398-403.

31. Ozer E, Canda T, Kuyucuodlu F. p53 mutations in bilateral breast carcinoma. Correlation with Ki-67 expression and the mean nuclear volume. Cancer Lett 1998;122:101-6.

32. Raouf A, Evoy D, Carton E, Mulligan E, Griffin M, Sweeney E, et al. Spontaneous and inducible apoptosis in oesophageal adenocarcinoma. Br J Cancer 2001;85:1781-6.

33. Slootweg PJ, Koole R, Hordijk GJ. The presence of p53 protein in relation to Ki-67 as cellular proliferation marker in head and neck squamous cell carcinoma and adjacent dysplastic mucosa. Eur J Cancer B Oral Oncol 1994;30B:138-41.

34. Suto T, Sugai T, Nakamura S, Funato O, Nitta H, Sasaki R, et al. Assessment of the expression of p53, MIB-1 (Ki-67 antigen), and argyrophilic nucleolar organizer regions in carcinoma of the extrahepatic bile duct. Cancer 1998;82:86-95.

35. Tateyama H, Eimoto T, Tada T, Mizuno T, Inagaki H, Hata A, et al. p53 protein expression and p53 gene mutation in thymic epithelial tumors. An immunohistochemical and DNA sequencing study. Am J Clin Pathol 1995;104:375-81.

36. Lardinois D, Rechsteiner R, Lang RH, Gugger M, Betticher D, von Briel C, et al. Prognostic relevance of Masaoka and Müller-Hermelink classification in patients with thymic tumors. Ann Thorac Surg 2000;69:1550-5.

37. Okumura M, Miyoshi S, Fujii Y, Takeuchi Y, Shiono H, Inoue $\mathrm{M}$, et al. Clinical and functional significance of WHO classification on human thymic epithelial neoplasms: a study of 146 consecutive tumors. Am J Surg Pathol 2001;25:103-10. 